\title{
ALMA, a new tool for the management of asthma patients in clinical practice: development, validation and initial clinical findings
}

\section{Hampus Kiotseridis, ${ }^{a, b}$, Leif Bjermer ${ }^{a}$, Eva Pilmanc, Björn Ställbergd, Kerstin Romberg ${ }^{\mathrm{a}, \mathrm{e}}$, *Alf Tunsäter ${ }^{a}$}

\footnotetext{
a Skåne University Hospital, Department of Respiratory Medicine and Allergology, Institute for Clinical Science, Lund University, Sweden

b Skåne University Hospital, Department of Pediatrics, Institute for Clinical Science, Lund University, Sweden

Laröds Primary Care Centre, Helsingborg, Sweden

${ }^{d}$ Department of Public Health and Caring Science, Family Medicine and Clinical Epidemiology, Uppsala University, Sweden

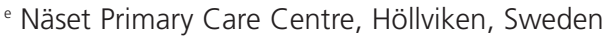

Received 28th February 2011; resubmitted 18th May 2011; revised version received 20th July 2011; final revision 3rd September 2011; accepted 4th September 2011; online 10th January 2012

\begin{abstract}
Background: Several instruments have been developed for measuring asthma control, but there is still a need to provide a structure for primary care asthma reviews.

Aims: The Active Life with Asthma (ALMA) tool was developed with the aim of structuring patient visits and assessing asthma treatment in primary care. The ability of ALMA to map out the care of asthma patients was evaluated and validated.

Methods: ALMA was developed with patient and clinical expert input. Questions were generated in focus groups and the resulting tool was subsequently validated by factor analysis in 1779 patients (1116 females) of mean age 51 years (range 18-89) in primary care.

Results: The ALMA tool includes 19 questions, 14 of which belong to a subset assessing asthma control. In this subset, factor analysis revealed three domains (factors): physical, psychological, and environmental triggers. Correlation with the Asthma Control Questionnaire was 0.72 and the Cronbach's alpha was 0.88 . The test-retest reliability was 0.93 . Of the 1779 patients tested with ALMA in primary care, $62 \%$ reported chest tightness, 30\% nightly awakenings and $45 \%$ asthma breakthrough despite medication.

Conclusions: The ALMA tool is useful as a follow-up instrument in clinical practice to structure patient visits and assess asthma treatment in primary care. The breadth of the questions and the pragmatic use in clinical practice also make it useful as an outcome measure.

(C) 2012 Primary Care Respiratory Society UK. All rights reserved.

H Kiotseridis et al. Prim Care Respir J 2012; 21(2): 139-144

http://dx.doi.org/10.4104/pcrj.2011.00091
\end{abstract}

Keywords asthma, outcome assessment, patient care, primary health care, quality of life, questionnaires

See linked editorial by Pinnock \& Lester on pg 122

The full version of this paper, with online appendix, is available online at www.thepcrj.org

\section{Introduction}

Regular asthma reviews are recommended by international guidelines to improve asthma morbidity, and there is a need for a simple structure to facilitate this in routine primary care practice. A special instrument to structure patient visits and assess asthma treatment in primary care - where restrictions on time and resources necessitate a simple and robust assessment procedure - would facilitate these reviews. An important part of these reviews is to assess asthma control. Despite the knowledge that the goal of asthma treatment is to achieve clinical control which implies minimal symptoms and use of reliever medication, no limitations in everyday activities, normal lung function, and no side effects from medication ${ }^{1}$ - several surveys have suggested

\footnotetext{
* Corresponding author: Dr Alf Tunsäter, Department of Respiratory Medicine and Allergology, Lund University, Skåne University Hospital, Lund, Sweden. Tel: +46-46-175857 E-mail: Alf.Tunsater@med.lu.se
} 
that both patients and physicians overestimate the level of asthma control. ${ }^{2-5}$ Many patients perceive their asthma to be mild and well controlled despite reporting frequent symptoms. ${ }^{2,3,5,6}$ Also, asthma patients have low adherence to treatment guidelines ${ }^{2,47-12}$ and poor knowledge of the disease. ${ }^{7}$ Written personal management plans exist but are only of limited use. ${ }^{5,7,13}$

Several instruments have been developed for measuring asthma control - for example, the Asthma Control Questionnaire (ACQ), ${ }_{1}^{14}$ the Asthma Control Test (ACT) ${ }^{15}$ and, for measuring health-related quality of life (HRQL), the Asthma Quality of Life Questionnaire (AQLQ), ${ }^{16}$ and the shorter version, the Mini-Asthma Quality of Life Questionnaire (Mini-AQLQ). ${ }^{17}$ Some of these are suited for primary care usage, but there is still a need for a special instrument to structure patient visits and assess asthma treatment in primary care.

The Active Life with Asthma (ALMA) tool aims to provide a structure for a primary care asthma review. The instrument should be easy to use in clinical practice and help structure patient visits. A core function of an asthma review is to assess control, so a part of the overall function of the tool will be to deal with this task.

In this study we aimed to compare a subset of questions on asthma control in the ALMA tool with the well-validated instrument $\mathrm{ACQ} .{ }^{14}$

\section{Methods}

Development of the ALMA tool for structuring asthma reviews

The developmental process of the questionnaire is shown in Figure 1. First, two discussion groups composed of up to eight asthma patients and chaired by an asthma specialist met to discuss everyday life with asthma, focusing on issues related to the disease. The patients were recruited from primary care and were equally distributed with regard to gender and age. They were divided into two age groups: younger (19-35 years) and older (>50 years). The aim was to find unmet needs reflecting real-life problems for patients with asthma. The discussions resulted in a set of questions. After reconciliation by the study committee, 25 questions were reduced to 19,14 of which concerned asthma control. The questions excluded were considered not to be relevant to this questionnaire (e.g. need for asthma education), although they were used for the basis of our educational programme. A pilot questionnaire was run in 10 primary care health centres (10 patients at each centre giving a total of 100 patients) to make sure that the questions were perceived correctly. The questions were subsequently evaluated and modified (minor wording changes) in collaboration with experienced asthma specialists and a draft version was established. The resulting tool consisted of 19 questions: 16 questions with four alternative answers (often, sometimes, seldom, never), two questions with yes/no answers, and one question about as-needed medication (see Appendix 1, available online at www.thepcrj.org). The paper-based form was
Figure 1. Flowchart showing the ALMA development process. 1. Initial focus groups for question generation (two groups). 2. Pilot questionnaire run on 100 asthma patients for perception of questionnaire (wording, layout, etc). 3. Test-retest reliability on asthma patients in primary care (questionnaire completion twice with 2 weeks between in parallel with ACQ; 200 patients). 4. Database construction and larger scale testing of questionnaire, and validation of a subset of asthma control questions including factor analysis (1779 patients). 5. Final version of ALMA tool

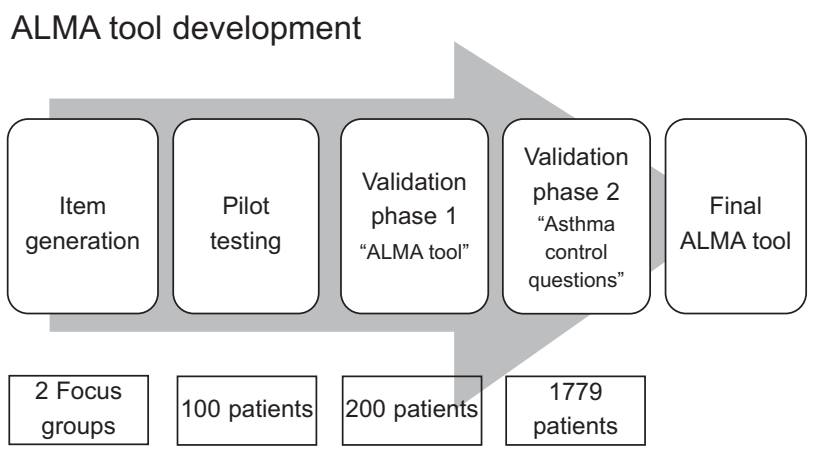

completed by the patient or the medical staff at an interview and took about 5 mins to complete.

Validation of the subset of asthma control questions In order to validate the subset of asthma control questions, the results of the 14 questions were compared with the answers to the ACQ, a 5-question questionnaire developed by Juniper et al..$^{14}$ Its ability to measure the degree of asthma control has been validated, and it was expected that the results of these instruments would correlate positively.

The questionnaire was sent out twice, 2 weeks apart, for assessing the test-retest reliability. The first questionnaire was sent out to 200 consecutive patients with doctor-diagnosed asthma in primary care who had earlier attended for asthma review. The second questionnaire was sent out to patients who had completed the first one.

The study was approved by the local ethics committee.

\section{Creation of the ALMA tool database}

To further validate the questionnaire with a larger patient sample, a database was constructed. In addition to the questionnaire results, questions by a medical specialist about smoking habits, current asthma medications, inhalation technique, spirometry, evaluation of treatment control, and actions taken are added and entered in a web-based application (ALMA database) with password-protected access. Each form covers information from three visits with variable time periods in between, reflecting the regular visit schedule. Patients aged $>18$ years with a diagnosis of asthma are qualified to fill in the questionnaire and the healthcare staff selects the eligible 
patients. In the initial phase, two primary care centres used the database; other practices were subsequently recruited. As the intention was to develop a tool for use in primary care clinics, no eligibility criteria were set. The primary care centres joined the database consecutively as they showed interest. In Sweden the primary care centres cover geographical areas and can thus be expected to have similar patient populations. ALMA was optional to use for both primary care centres and patients.

The data were stored in a database at the Allergy Competence Centre (Swedish; AKC) in Lund, Sweden. The patient questionnaire form and written consent form were archived at the respective primary care centres. The doctors at the primary care centres had access to individual patient data and to summaries of data at the centre and country level.

The resulting database was then used for further validation of the subset of asthma control questions in the ALMA tool by factor analysis.

\section{Statistical analysis}

For computational reasons, the 19 questions were numerically coded: 1-4 (questions 1-16), 1- 2 (questions 17 and 18) or 1-3 (question 19). Descriptive statistics were calculated for each question and numerical background variables. Correlation coefficients between questions and lung function variables were also calculated. For cross-sectional validity the results were compared with the ACQ results. Cronbach's alpha coefficient was used for internal validity. Test-retest reliability was calculated by Pearson's correlation coefficient.

An exploratory factor analysis was undertaken to investigate the structure among the 19 questions and to determine if there were groupings (factors) among them indicating different domains. The applied extraction method was axis factoring. A scree plot was constructed. Since the correlation matrix suggested correlation between factors, we used an oblique rotation.

The statistical tests were performed in SPSS Statistics 18 for Windows (IBM Corporation, Somers, NY, USA). A p value $<0.05$ was regarded as statistically significant.

\section{Results}

\section{Validation of the subset of control questions}

Both the ALMA and ACQ questionnaires were sent out to 200 consecutive patients (114 women) of median age 41 years (range 18-76); 131 patients (62 women) answered the first questionnaire. The second questionnaire, sent to patients who answered the first questionnaire, was completed by 77 patients (47 women). There was no difference in age or gender in those who did not complete the questionnaire. The mean ACQ score did not change during the 2-week test period (0.78 and 0.8, respectively; range $0-4$ ).

The correlation between ALMA and ACQ was 0.71 , showing good cross-sectional validity. The internal validity measured with Cronbach's alpha was 0.91 and the test-retest reliability was 0.93 .
Table 1. Subset of asthma control questions in the ALMA tool: factor analysis - rotated factor pattern

\begin{tabular}{llll} 
& Factor 1 & Factor 2 & Factor 3 \\
\hline 1. Chest tightness & $0.53^{*}$ & 0.10 & 0.13 \\
\hline 2. Coughing & $0.52^{*}$ & 0.05 & 0.04 \\
\hline 3. Dust, pollen, furred animals & -0.21 & 0.16 & $0.53^{*}$ \\
\hline 4. Cold outdoors & 0.25 & -0.11 & $0.49^{*}$ \\
\hline 5. Tobacco smoke/strong odours & -0.01 & .0 .04 & $0.58^{*}$ \\
\hline 6. A cold & 0.25 & -0.11 & $0.46^{*}$ \\
\hline 7. Worry about asthma & 0.05 & $0.64^{*}$ & -0.16 \\
\hline 8. Affects life & 0.21 & $0.90^{*}$ & -0.10 \\
\hline 9. Refrain & 0.11 & $0.63^{*}$ & 0.10 \\
\hline 10. Walking & $0.88^{*}$ & 0.01 & -0.12 \\
\hline 11. Heavy work & $0.83^{*}$ & 0.00 & -0.07 \\
\hline 12. Sports activities & $0.57^{*}$ & 0.05 & 0.05 \\
\hline 13. Night-time awakening & $0.47^{*}$ & 0.14 & 0.03 \\
\hline 14. Wheezing & $0.55^{*}$ & 0.00 & -0.00 \\
\hline *Component loading on factor $>0.4$. & & &
\end{tabular}

Figure 2. Scree plot after axis factoring analysis for the subset of asthma control questions signalling for few factors. A four-factor solution resulted in questions concerning physical problems in two different factors. Three factors were chosen for a more stable solution

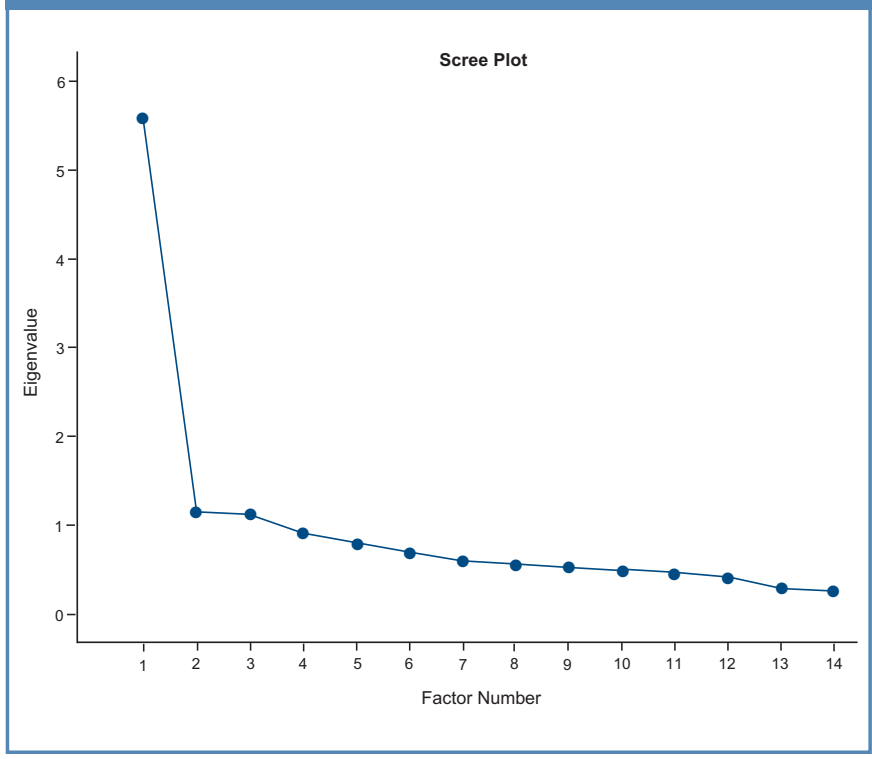

Factor analysis of the subset of control questions

Principal axis factoring revealed a scree plot suggesting few factors. After exploring different solutions, a three-factor solution was found to be most appropriate, with three logical domains: physical, mental, and environmental. The correlation matrix showed correlations between the factors, suggesting an oblique rotation as most appropriate. The rotated factor pattern showed that the 14 items loaded onto one of the three factors 


\section{Table 2. Patient characteristics}

\begin{tabular}{ll} 
Characteristics & Data \\
\hline Patients, $n$ & 1779 \\
\hline Male/female gender & $663 / 1116(37 / 63)$ \\
\hline Age, years & $51.0(17.8),($ range 18-89) \\
$\leq 45$ & $716(40.2)$ \\
$>45$ & $1063(59.8)$ \\
\hline Smoking habits & $1112(62.5)$ \\
Non-smokers & $482(27.1)$ \\
Ex-smokers & $185(10.4)$ \\
Smokers & $1150(64.6)$ \\
\hline Current asthma medications & $299(16.8)$ \\
Short-acting $\beta_{2}$-agonist & $903(50.8)$ \\
Long-acting $\beta_{2}$-agonist & $682(38.3)$ \\
Inhaled corticosteroids & $100(5.6)$ \\
Combination therapy & $215(12.1)$ \\
Antileukotrienes & $71(4.0)$ \\
Other medication & \\
No medication & $85.5(19.0)$
\end{tabular}

with a value of $>0.4$ (Table 1). The scree plot is shown in Figure 2. Cronbach's $\alpha$ for the whole scale was 0.88 (0.86 for the physical factor, 0.59 for the mental factor, and 0.51 for the environmental factor). Correlation with the ACQ score was 0.72 . The test-retest results computed was 0.93 ( 0.92 for the physical factor, 0.88 for the mental factor, and 0.81 for the environmental factor).

\section{Results from ALMA tool database}

Patient characteristics and background data are presented in Table 2. Figure 3 illustrates the response to the ALMA questions of 1779 patients on their first visit.

Two-thirds of the patients (62\%) reported chest tightness on a regular basis (defined as often or sometimes). Many patients had asthma aggravations when exposed to dust, pollen, furred animals $(61 \%)$, tobacco smoke, strong odours (62\%), and cold weather outdoors (68\%). Most patients (84\%) reported that the presence of a cold aggravated the asthma. Physical activity such as walking, heavy work and sports affected about half of those questioned $(48 \%, 50 \%$, and $53 \%$, respectively), almost onethird (30\%) reported nocturnal awakening and $45 \%$ reported asthma breakthrough (defined as having asthma symptoms despite prescribed intake of asthma medication). Few patients (15\%) experienced adverse medication effects. During the previous year, $21 \%$ of the patients had an emergency room visit due to asthma but only $2.5 \%$ had been hospitalised. As-needed

Figure 3. Results of the individual questions in the ALMA questionnaire on the patients so far registered in the database (age 18-89 years)

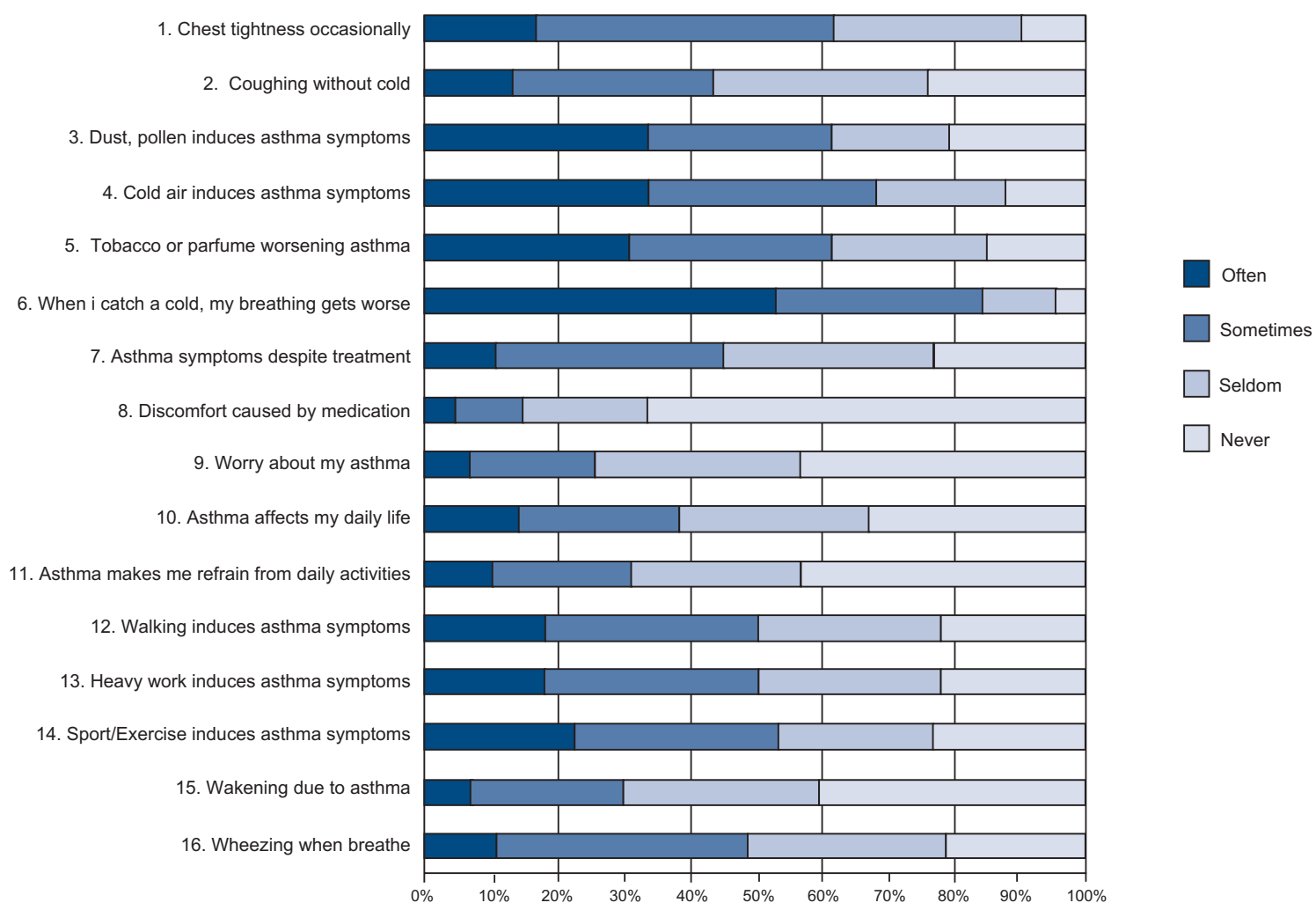


medication above the recommended dosage guidelines was used by $25 \%$ of patients.

The correlation between ALMA items and lung function as measured by forced expiratory volume in 1 second $\left(\mathrm{FEV}_{1}\right)$ was between -0.12 and 0.05 .

The ALMA score also differed significantly in the group judged at the clinic as being undertreated by the staff (mean total score 37.8 and 45.9 , respectively, $\mathrm{p}<0.001$ ).

\section{Disaussion}

\section{Main findings}

Evaluation of the new ALMA tool and validation of the subset of asthma control questions demonstrated that the items selected cover key areas in an auditable structure for primary care asthma reviews (e.g. physical restrictions, environmental triggers, psychological function and healthcare utilisation). These are important aspects when assessing patients with asthma, and we believe that the use of the ALMA tool helps to structure this evaluation. A core function of an asthma review is to assess control, and as we have shown good correlation with an established instrument for this purpose (ACQ), we think that the ALMA tool also fulfils this requirement.

\section{Strength and limitations of this study}

The strength of the study is the careful development and validation which was done in three steps, all including real-life patients to ensure its usefulness in the clinical setting. The validation of the asthma control questions included 1779 patients, which is also a strength of the study.

We chose in the ALMA questionnaire not to have a specified recall period. There is no gold standard for the recall time period, and different items might have different time frames depending on the nature of the item. ${ }^{18} \mathrm{~A}$ short time period might give a more accurate recall for that period but, in clinical practice when the patient sees the doctor a few times every year, to have an open time frame gives the patient the possibility to assess and capture a broader range of experiences.

The high test-retest reliability shows that the ALMA instrument is very stable. The Cronbach's alpha is high, which makes it suitable as a follow-up instrument. ${ }^{19}$ One limitation of the study is that the selection of which patients to include was random and may introduce bias, e.g. patients with more severe asthma may be registered and those with milder disease may not be included.

The correlation between ALMA and the ACQ was high (0.72), which indicates that the ALMA instrument covers the aspects of asthma control. It would have been preferable to have more scales for comparison in the validation process.

Interpretation of findings in relation to previously published work

In this study a large proportion of the patients still had signs of suboptimal treatment with chest tightness, nightly awakenings and asthma aggravations caused by environmental triggers, which has also been observed in earlier studies. ${ }^{2.5}$ There was a weak correlation between objective lung function measurements such as FEV 1 and the HRQL according to the ALMA instrument, consistent with previous findings. ${ }^{20-22}$

Clinical measures such as $\mathrm{FEV}_{1}$ provide useful information but fall short in their ability to capture the broad impact of asthma on quality of life. A broad-based self-report measure that permits integration of multiple disease effects can fulfil some important requirements for a follow-up instrument in clinical practice.

The three domains found in the ALMA subset of control questions covers aspects of asthma measured by other instruments (AQLQ and Mini-AQLQ) and is comprehensive for clinical follow-up. The AQLQ and Mini-AQLQ quantify HRQL in a clinical trial setting and some measures of asthma control. ${ }^{23}$ However, these asthma control and HRQL instruments are not fully optimal for a real-life setting as none of them cover the complete evaluation of the daily life of asthma patients to be considered in primary care. Although the principal use of the ALMA instrument is as an audit tool to structure primary care asthma reviews, it also covers important areas for the clinical assessment of asthma control in primary care. As such, it can be used to assess changes since the last visit and the possible need for treatment change. The ALMA tool also provides a useful educational complement for both patients and doctors/healthcare nurses with data summaries at the individual level. It can also be used on a regional level to give feedback on asthma care.

Implications for future research, policy and practice

Further validation will continue to be done as the ALMA database is open-ended, and follow-up data - as well as data on new patients - will be entered continuously. Sensitivity will be tested by evaluation of emergency room visits and hospitalisations. Annual data compilations are planned and a web-based application will soon be introduced and validated against the paper version.

\section{Conclusions}

The breadth of the questions in the ALMA tool and the pragmatic use in clinical practice suggest that it can form the basis of a structured review in primary care which may translate into improved outcomes. The good correlation with the ACQ indicates that it can also be useful in assessing asthma control, which is a core function of an asthma review.

Handling editor Hilary Pinnock

Statistical review Gopal Netuveli

Acknowledgements The authors are grateful to all the patients in the study as well as the nurses at the clinics for their assistance in patient selection and data collection. We thank Klas Svensson for his advice with statistics and Caroline Silwer for her assistance with data collection.

Conflicts of interest The authors declare that they have no conflicts of interest in relation to this article. BS is an Associate Editor of the $P C R J$, but was not involved in the editorial review of, nor the decision to publish, this article.

Contributorship AT contributed to the conception and design of the study. $E P, K R$ were responsible for recruitment of patient in the development and validation phase. $H K, A T, L B, B S$ were responsible for analysis and interpretation of the data and drafting of the manuscript. All authors contributed to the intellectual content and 
critical revision of the manuscript.

Funding The study was supported by an unrestricted educational grant from AstraZeneca.

\section{References}

1. Bateman ED, Hurd SS, Barnes PJ, et al. Global strategy for asthma management and prevention: GINA executive summary. Eur Respir J 2008;31(1):143-78. http://dx.doi.org/10.1183/09031936.00138707

2. Rabe KF, Vermeire PA, Soriano JB, Maier WC. Clinical management of asthma in 1999: the Asthma Insights and Reality in Europe (AIRE) study. Eur Respir J 2000;16(5):802-07. http://dx.doi.org/10.1183/09031936.00.16580200

3. Stallberg B, Nystrom Kronander U, Olsson P, Gottberg L, Ronmark E, Lundback B. Living with asthma in Sweden--the ALMA study. Respir Med 2003;97(7):835-43. http://dx.doi.org/10.1016/S0954-6111(03)00040-4

4. Partridge MR, van der Molen T, Myrseth SE, Busse WW. Attitudes and actions of asthma patients on regular maintenance therapy: the INSPIRE study. BMC Pulm Med 2006;6:13. http://dx.doi.org/10.1186/1471-2466-6-13

5. Haughney J, Barnes G, Partridge M, Cleland J. The Living \& Breathing Study: a study of patients' views of asthma and its treatment. Prim Care Respir J 2004;13(1):2835. http://dx.doi.org/10.1016/j.pcrj.2003.11.007

6. Nguyen BP, Wilson SR, German DF. Patients' perceptions compared with objective ratings of asthma severity. Ann Allergy Asthma Immunol 1996;77(3):209-15. http://dx.doi.org/10.1016/S1081-1206(10)63257-7

7. Taylor DM, Auble TE, Calhoun WJ, Mosesso VN, Jr. Current outpatient management of asthma shows poor compliance with International Consensus Guidelines. Chest 1999;116(6):1638-45. http://dx.doi.org/10.1378/ chest.116.6.1638

8. Bender $B$, Milgrom $H$, Rand $C$. Nonadherence in asthmatic patients: is there a solution to the problem? Ann Allergy Asthma Immunol 1997;79(3):177-85; quiz 185-6. http://dx.doi.org/10.1016/S1081-1206(10)63001-3

9. Kinsman RA, Dirks JF, Dahlem NW. Noncompliance to prescribed-as-needed (PRN) medication use in asthma: usage patterns and patient characteristics. I Psychosom Res 1980;24(2):97-107.

http://dx.doi.org/10.1016/0022-3999(80)90059-8

10. Cerveri I, Locatelli F, Zoia MC, Corsico A, Accordini S, de Marco R. International variations in asthma treatment compliance: the results of the European Community Respiratory Health Survey (ECRHS). Eur Respir J 1999;14(2):288-94. http://dx.doi.org/10.1034/j.1399-3003.1999.14b09.x
11. Jonasson G, Carlsen KH, Sodal A, Jonasson C, Mowinckel P. Patient compliance in a clinical trial with inhaled budesonide in children with mild asthma. Eur Respir $J$ 1999;14(1):150-4. http://dx.doi.org/10.1034/.1399-3003.1999.14a25.x

12. Veazie PJ, Cai S. A connection between medication adherence, patient sense of uniqueness, and the personalization of information. Med Hypotheses 2007;68(2):335-42. http://dx.doi.org/10.1016/j.mehy.2006.04.077

13. Ordonez GA, Phelan PD, Olinsky A, Robertson CF. Preventable factors in hospital admissions for asthma. Arch Dis Child 1998;78(2):143-7. http://dx.doi.org/10.1136/adc.78.2.143

14. Juniper EF, O'Byrne PM, Guyatt GH, Ferrie PJ, King DR. Development and validation of a questionnaire to measure asthma control. Eur Respir J 1999;14(4):902-7. http://dx.doi.org/10.1034/j.1399-3003.1999.14d29.x

15. Nathan RA, Sorkness CA, Kosinski M, et al. Development of the asthma control test: a survey for assessing asthma control. J Allergy Clin Immunol 2004;113(1):59-65. http://dx.doi.org/10.1016/j.jaci.2003.09.008

16. Juniper EF, Guyatt GH, Epstein RS, Ferrie PJ, Jaeschke R, Hiller TK. Evaluation of impairment of health related quality of life in asthma: development of a questionnaire for use in clinical trials. Thorax 1992;47(2):76-83. http://dx.doi.org/10.1136/thx.47.2.76

17. Juniper EF, Guyatt GH, Cox FM, Ferrie PJ, King DR. Development and validation of the Mini Asthma Quality of Life Questionnaire. Eur Respir J 1999;14(1):32-8. http://dx.doi.org/10.1034/.1399-3003.1999.14a08.x

18. Stull DE, Leidy NK, Parasuraman B, Chassany O. Optimal recall periods for patientreported outcomes: challenges and potential solutions. Curr Med Res Opin 2009;25(4):929-42. http://dx.doi.org/10.1185/03007990902774765

19. Bland JM, Altman DG. Cronbach's alpha. BMJ 1997;314:572.

20. Juniper EF, Wisniewski ME, Cox FM, Emmett AH, Nielsen KE, O'Byrne PM. Relationship between quality of life and clinical status in asthma: a factor analysis. Eur Respir J 2004;23(2):287-91. http://dx.doi.org/10.1183/09031936.04.00064204

21. Ehrs PO, Aberg H, Larsson K. Quality of life in primary care asthma. Respir Med 2001;95(1):22-30. http://dx.doi.org/10.1053/rmed.2000.0967

22. Ehrs PO, Sundblad BM, Larsson K. Quality of life and inflammatory markers in mild asthma. Chest 2006;129(3):624-31. http://dx.doi.org/10.1378/chest.129.3.624

23. Vollmer WM, Markson LE, O'Connor E, et al. Association of asthma control with health care utilization and quality of life. Am J Respir Crit Care Med 1999;160(5 Pt 1):1647-52.

\section{Available online at http://www.theprj.org}


Appendix 1

The translation from Swedish to English is linguistic and has not been validated for health care use.

ALMA tool: Questions 1-19

Subset of asthma control questions: Questions 1-14

\section{Question}

\section{Domain}

1 Jag känner mig trång i bröstet. I have chest tightness.

2 Det händer att jag får kraftiga hostattacker även om jag inte är förkyld. I may get severe coughing even though I don't have a cold.

3. Damm, pollen och/eller pälsdjur gör mina luftrör sämre. Dust, pollen and/or furred animals aggravate my asthma.

$4 \quad$ När det är kallt ute blir jag sämre i luftrören och det blir tungt att andas When it's cold outside my asthma gets worse and it's hard to breathe.

5 Då jag utsätts för tobaksrök eller starka dofter får jag tungt att andas. Environmental When I'm exposed to tobacco smoke or strong odours it's hard to breathe.

6 Där jag är förkyld blir jag sämre i luftrören och det känns tungt att andas. When I catch a cold my asthma gets worse and it's hard to breathe.

$7 \quad$ Jag tänker på och oroas av min astma. I think about and worry about my asthma.

8. Min astma påverkar mitt liv mer än jag vill. Mental My asthma affects my life more than I want to.

9. Jag måste avstå från sådant jag vill göra p.g.a. min astma. I have to give up things I want to do because of my asthma.

10. När jag promenerar eller anstränger mig måttligt får jag hosta eller andnöd. When I walk or exhaust myself moderately, I get cough and shortness of breath.

11. När jag utför tyngre arbete får jag hosta eller andnöd. When I perform heavy work, I get a cough and shortness of breath.

12. När jag deltar i sportaktiviteter får jag problem med hosta eller andnöd. When I participate in sports activities, I get a cough or shortness of breath.

13. När jag sover händer det att jag vaknar av hosta eller andnöd. When I'm sleeping, I may wake up by coughing or shortness of breath.

14. Det piper i bröstet när jag andas. I wheeze when I breathe.

15. Under det senaste året har jag sökt akut för astmabesvär. During the past year I've visited an emergency room because of asthma symptoms.

16. Under det senaste året har jag blivit inlagd på sjukhus p.g.a. astmabesvär. During the past year I've been admitted to hospital because of asthma symptoms.

17. Jag använder min vid-behovs-medicin ( $\leq 2 \mathrm{ggr} / \mathrm{v}$ eller $>2 \mathrm{ggr} / \mathrm{v}$ ). I use my rescue medication ( $\leq 2$ times a week or $>2$ times a week).

18. Det händer att jag får astmabesvär trots att jag tar min astmamedicin så som doktorn har sagt. I may have asthma symptoms even though I take my medication as prescribed by my doctor.

19. Jag upplever obehag av min astmamedicin. My asthma medication causes discomfort.

Questions 1-14 answered on an ordinal scale with alternatives (often, sometimes, seldom, never). 